\title{
Acidente de trabalho em sistemas de produção: abordagem e prevenção
}

\author{
Work accident in production system in bahia, brazil: \\ approach and prevention
}

\author{
Anastácio Pinto Gonçalves Filho'1 \\ Magna Fernandes Ramos ${ }^{2}$
}

\begin{abstract}
Resumo: O objetivo deste artigo é apresentar uma pesquisa desenvolvida com a finalidade de conhecer que tipo de abordagem é adotado pelos sistemas de produção instalados no Estado da Bahia nas análises de acidente de trabalho. O conhecimento desta abordagem possibilita saber se os sistemas de produção evoluíram ao longo dos anos com relação às análises de acidentes e compreender se essas análises estão contribuindo com seu objeto primordial: prevenção efetiva e duradoura. Os autores analisaram 85 relatórios de 46 sistemas produção, para identificar a abordagem adotada nas análises de acidentes. Constata-se que os sistemas produção pesquisados não evoluíram com relação à análise de acidentes, continuam ainda presos a uma abordagem que privilegia as ações com foco no indivíduo. Os autores criticam a abordagem utilizada, discutindo a necessidade de mudança da gestão de segurança, de modo a fornecer os elementos necessários e adequados à prevenção desse indesejável fenômeno, ainda grave problema de saúde pública no Brasil.
\end{abstract}

Palavras-chave: Prevenção; Acidente de trabalho; Gestão; Sistema de produção.

\begin{abstract}
This article aims to present a research developed to better understand what approach is adopted by the production systems installed in the State of Bahia, Brazil to analyze work accidents. Knowledge of this approach allows us to understand the production system improved in the past years regards accident analysis and to understand these analyzes contribute to its main goal: effective and lasting prevention. The authors analyzed 85 reports of 46 production systems to identify the approach used in accident analyzes. It appears that the surveyed production systems did not change regarding accident analysis, they are still stuck with an approach that emphasizes the analysis focused on individual actions. The authors criticize the approach, discussing the need for measures to change the safety management in order to provide the necessary and appropriate elements to prevent this undesirable phenomenon, still a serious public health problem in Brazil.
\end{abstract}

Keywords: Prevention; Work accident; Management; Production system.

\section{Introdução}

Os acidentes de trabalho são um dos maiores problemas de saúde pública em todo mundo e têm elevado ônus para toda a sociedade, sendo a sua redução um anseio de todos: governo, empresários e trabalhadores. Além da questão social, com morte e mutilação de operários, a importância econômica também é crescente. Além de causar prejuízos às forças produtivas, os acidentes geram despesas como pagamento de benefícios previdenciários, recursos que poderiam estar sendo canalizados para outras políticas sociais. Urge, portanto, reduzir o custo econômico e social mediante medidas de prevenção (Brasil, 2001).

Uma importante forma de prevenção é aprender sobre o que ocorre e sobre o que pode ocorrer em

um sistema produção. Um instrumento que contribui para esta aprendizagem é a análise de acidente, pois possibilita compreender os riscos, solucionar problemas e proteger pessoas (Brasil, 2010).

A maioria dos acidentes é previsível e prevenível e, ao contrário de constituir obra do acaso, como sugere a palavra "acidente", são fenômenos socialmente determinados, relacionados a fatores de risco presentes nos sistemas de produção, definidos aqui como um conjunto de atividades inter-relacionadas envolvidas na produção de bens (caso de indústrias) ou de serviços (Moreira, 2009). Nos sistemas de produção existem riscos e medidas de controle que devem ser adotadas para eliminá-los ou reduzi-los, a fim de prevenir acidentes. A ocorrência de um evento adverso indica

\footnotetext{
${ }^{1}$ Universidade Federal da Bahia - UFBa, Rua Aristides Novis, 2, Federação, Salvador, BA, Brasil, e-mail: anastaciofilho@ufba.br ${ }^{2}$ Ministério do Trabalho e Emprego, Av. Sete de Setembro, 689, Mercês, Salvador, BA, Brasil, e-mail: MagnaF@mte.gov.br
} Recebido em Jul. 29, 2013 - Aceito em Mar. 31, 2015

Suporte financeiro: Nenhum. 
que as medidas de controle de risco eram inadequadas ou insuficientes. Assim, o conhecimento derivado da análise do acidente amplia as possibilidades de prevenção, porque identifica onde o sistema de segurança falhou (Brasil, 2010). Destarte, uma boa análise de acidente constitui importante ferramenta para a prevenção.

Por outro lado, muitas análises de acidentes cometem os mesmos erros em relação à identificação de suas causas. Elas identificam o que quebrou ou funcionou mal, então localizam as pessoas mais próximas da falha técnica: o engenheiro que calculou mal, o operador que perdeu o sinal, o supervisor que falhou na escuta ou o gerente que tomou decisões erradas. Quando as causas são limitadas às falhas técnicas ou individuais, as respostas que objetivam prevenir acidentes similares no futuro são também limitadas: elas se restringem a consertar o problema técnico e substituir as pessoas responsáveis. Estas correções são potencialmente desastrosas, porque fazem acreditar que o problema de base (causa-raiz) foi resolvido (NASA, 2003).

Nesse contexto, para que a análise de acidentes atinja seu objetivo, que é a prevenção, é importante que não seja baseada na visão de que o sistema de produção é confiável e o ser humano constitui o elo frágil da corrente. Também é importante não considerar que as falhas humanas são decorrentes de fatores individuais e do desrespeito às normas prescritas, fruto de decisões "conscientes" dos trabalhadores. Desta forma, as medidas oriundas dessas análises não se resumirão a punições e a "treinamentos", medidas que não contribuem para uma prevenção de acidentes efetiva e duradoura.

O objetivo deste artigo é apresentar uma pesquisa desenvolvida com a finalidade de conhecer qual o tipo de abordagem de acidente é utilizada nas análises realizadas pelos sistemas de produção instalados no Estado da Bahia, Brasil. O conhecimento de como estão sendo analisados os acidentes no âmbito dos sistemas produtivos é de interesse da engenharia de produção, mais especificamente dos profissionais que atuam na área de gestão de segurança do trabalho, pois possibilita compreender, com base no referencial teórico descrito a seguir, se as análises de acidentes evoluíram e estão cumprindo com seu objetivo principal de prevenção de infortúnios para os trabalhadores, ou continuam atrelados a um paradigma que enfatiza o comportamento dos acidentados.

\section{Evolução das abordagens de análises de acidentes}

Serão apresentadas a seguir abordagens desenvolvidas por autores com origem em campos de conhecimento diversos, que abrangem como perspectivas gerais a incorporação de aspectos sociais, a consideração de problemas relacionados ao gerenciamento da produção e à organização do trabalho para a compreensão e intervenção sobre os acidentes de trabalho. Foram selecionados autores cujos trabalhos são mais referenciados e exercem influência com relação ao entendimento do fenômeno acidente. Não faz parte dos objetivos da pesquisa apresentada neste artigo dar um panorama completo dos desenvolvimentos da área da acidentologia ou propor novas abordagens sobre o tema.

Nas últimas décadas, os acidentes têm sido objeto de estudos da comunidade científica, com o objetivo de identificar e explicar os fatores que dão origem a estes eventos. Como resultado, contribuições de diferentes de pesquisadores surgiram, possibilitando diferentes métodos de análise (Dwyer, 2006; Perrow, 1999; Reason, 1997; Turner \& Pidgeon, 1997).

Hale \& Hovden (1998) identificam a existência de três momentos principais no estudo científico da segurança e análise de acidentes.

A primeira fase, cujo início pode ser marcado no início do século XIX até a Segunda Guerra Mundial, incidiu sobre medidas técnicas para evitar acidentes. Nesta fase, a principal preocupação incidiu sobre a análise das máquinas, as condições de trabalho e a prevenção implicavam uma solução técnica de modo a criar condições de segurança e proteção das pessoas em face dos perigos (fonte ou situação com potencial para provocar danos às pessoas e ao patrimônio), por exemplo, o equipamento de proteção individual. Nesta altura, as condições de trabalho eram ruins e a grande preocupação era a melhoria das condições físicas do ambiente de trabalho.

Essa abordagem deu origem a estudos para identificação de riscos químicos, físicos e biológicos e aos estudos dos efeitos de exposição a esses riscos para a saúde e segurança dos trabalhadores. Essa vertente ainda continua a ser estudada, principalmente por áreas como a química, a engenharia e a biologia.

A segunda fase remonta à década de 1920, mas teve um desenvolvimento mais substancial após a Segunda Guerra Mundial. O marco desta fase é a publicação dos trabalhos de Greenwood e Woods e de Heirinch em 1931, que introduziram a componente humana na análise dos acidentes de trabalho (Sarkus, 2001). A proposta de Greenwood e Woods em 1919 sobre a existência de propensão individual dos trabalhadores para os acidentes é referida como sendo a primeira teoria científica que procurou explicar os acidentes de trabalho incluindo fatores humanos (Cooper, 1998). Nessa altura, surge uma preocupação com o comportamento e erro humano, que deu origem à preocupação com a prevenção centrada no indivíduo. A concepção de acidente proposta por Greenwood e Woods dominou os pesquisadores e os especialistas em segurança por quase 50 anos. 
Na década de 1930, Heinrich propôs a primeira teoria na qual o acidente tem origem em uma sequência linear de eventos, que ele chamou de "teoria do dominó". Numa tentativa de sistematização que se contrapunha à noção de fatalidade, esta teoria representa o acidente por uma sequência de cinco pedras de dominó posicionadas de modo que a queda de uma desencadeia a queda das subsequentes (Almeida, 2006; Binder \& Almeida, 2003; Cooper, 1998).

A terceira pedra da série introduziu as noções de atos e de condições inseguros como fatores imediatamente precedentes ao acidente propriamente dito e à lesão. De acordo com essa teoria, as ações do trabalhador, ou de seus colegas, exercem papel de destaque e devem ser contempladas na prevenção.

Nessa fase, o acidente ainda é considerado um acontecimento simples que resulta de uma causa única, ou poucas causas, ou tem uma origem humana, ou tem uma origem técnica.

No Brasil, estudos realizados por diversos autores (Almeida, 2001; Brasil, 2003; Binder \& Almeida, 1997; Vilela et al., 2004) revelam que grande parte das investigações de acidentes ainda se baseia na concepção dicotômica de ato inseguro e de condições inseguras, frequentemente desembocando na atribuição de culpa ao trabalhador pelo evento que o vitimou e recomendando medidas de prevenção orientadas para mudanças de comportamento, sabidamente frágeis.

A terceira fase, com início no final dos anos 1970, incide na organização e em todos os fatores entrelaçados e que são considerados anteriormente. Essa fase é caracterizada pela causalidade múltipla, ou seja, o acidente é explicado por vários fatores que associam a interação entre o indivíduo, a situação de trabalho, os fatores de grupos, fatores organizacionais e o ambiente de trabalho. Esta fase surgiu devido à crescente insatisfação relativa à ideia de que a saúde e segurança poderiam ser caracterizadas apenas pela conjugação do indivíduo com a tecnologia (Silva, 2003).

Esse período é marcado por várias contribuições das ciências sociais para a explicação das origens dos acidentes, que vieram salientar os componentes técnico-organizacionais, relações sociais, institucionais e sociais, que estão na origem do acidente. É possível identificar dois fatores que desencadearam essa nova forma de compreender e explicar os acidentes. Em primeiro lugar, a ocorrência de grandes acidentes nos anos 1970 e 1980 colocam as explicações vigentes insuficientes e instiga os investigadores a desenvolverem novas explicações. Em segundo lugar, numa análise pioneira de vários grandes acidentes, Turner \& Pidgeon (1997) colocam os fatores organizacionais no centro das atenções dos acidentes industriais também. O livro Man-made disasters, de sua autoria, é o marco do novo rumo teórico e empírico. Turner \& Pidgeon (1997) propõem uma explicação dos acidentes que enfatizam a contribuição dos fatores sociais, de gestão e administrativos presentes no funcionamento organizacional. Especificamente, defende que as crenças, normas e práticas organizacionais são a "essência" à sequência de acontecimentos que dá origem a um acidente.

Desde então, têm sido realizados vários estudos empíricos e propostos vários modelos teóricos com o intuito de identificar e analisar a influência de fatores sociais e organizacionais sobre a segurança e acidentes. Embora a literatura registre polêmicas entre os autores citados, pode-se dizer que as principais contribuições ao estudo dos acidentes são as seguintes.

Perrow (1999) introduziu o conceito de normal accident ou sistêmico, incluindo a diferenciação entre falha de componentes e falha sistêmica, os conceitos de complexidade (interações lineares ou simples e complexas) e de força de acoplamento de interações. Para ele, os acidentes são inevitáveis, são "normais" em sistemas complexos, sistemas de grande tamanho e de interatividade complexa, que tem de funcionar de forma estreitamente interligada, ou seja, incluem muitos processos dependentes do tempo e sequências interdependentes. Segundo este autor, isso acontece porque aumenta a probabilidade de ocorrerem interações inesperadas entre componentes ou experiências dificilmente compreensíveis. Segundo Perrow (1999), as falhas nesses sistemas ocorrem devido a três tipos principais de problemas: pressões da produção, investigações de acidentes simplistas e redutoras e à "socialização do risco", que significa que pessoas ou propriedades podem estar expostas ao risco e sofrer suas consequências, mesmo que não estejam diretamente relacionadas com ele. Como exemplo, para melhor compreensão do leitor, citam-se as comunidades vizinhas às grandes empresas químicas ou petroquímicas, que podem ser atingidas por um vazamento de um produto tóxico ou por uma explosão nessas empresas.

A abordagem sistêmica de acidente proposto por Reason (1997) inclui o conceito de condições latentes, que estariam na origem dos acidentes. Segundo ele, as condições latentes estão relacionadas às decisões gerenciais, à cultura, investimentos, políticas dos líderes, tecnologias e materiais utilizados na organização, práticas de manutenção, etc. Para Reason (2006), os erros ativos, aqueles praticados pelos trabalhadores imediatamente antes dos acidentes, têm pouca importância para a prevenção de acidentes e, por sua vez, a correção das condições latentes é apontada como fundamental para a prevenção desses eventos.

Para Llory (1999), o acidente deve ser compreendido como fator que esteve não só adormecido ou latente, mas incubado no sistema. Devem ser considerados e analisados, durante a investigação dos acidentes, aspectos da história da organização, tanto no nível das dimensões particulares de cada um dos sujeitos que a compõe, quanto nos níveis das relações 
interpessoais, horizontais e verticais que se formaram e se estabeleceram historicamente nas situações de trabalho. Ele afirma ainda que a abordagem centrada no individuo (comportamentalista) não esclarece e, ao contrário, obscurece a compreensão de como o acidente ocorreu. Ele defende que as investigações de acidentes devem contemplar as descrições subjetivas, incluindo as intenções dos atores, as palavras usadas, as discussões e os elementos presentes nos momentos que antecedem às tomadas de decisões e que é preciso estender as análises também para os incidentes, os quase acidentes e as situações de atividades habituais sem acidentes. A prevenção eficaz só é conseguida se todos os atores da empresa tiverem espaço garantido e efetivo de discussão, debate, explanação dos problemas e das dificuldades vividas na rotina de trabalho normal e participação na busca por resoluções dos problemas encontrados e também nas tomadas de decisão.

Autores identificados com o enfoque cognitivo em ergonomia (Amalberti, 1996; Guerin et al., 2001) apresentam importante contribuição para o entendimento dos acidentes nos ambientes de trabalho, quando destacam a relevância das representações e das comunicações sobre a problemática do "erro humano". Para esses autores, quando ocorre um incidente ou um acidente grave em um sistema de produção, fala-se frequentemente em "erro humano", no sentido de que "alguém deveria ter feito algo diferente do que fez". No entanto, esse modo de falar, segundo eles, não ajuda muito a evitar uma repetição do acidente, pois a conduta desejada frequentemente é constituída só após o ocorrido, a partir de informações diferentes daquelas que o trabalhador dispunha no momento e fora dos constrangimentos, em particular os temporais, que se impunham a eles. Por outro lado, essa formulação evita que se procurem os determinantes de uma conduta não apropriada em termos de concepção dos meios de produção. Se erros foram cometidos, possivelmente o foram na concepção dos dispositivos técnicos, na escolha da apresentação da informação, na organização do trabalho, na definição da formação, etc.

Outra proposta de abordagem para explicar os acidentes centrou-se nas relações sociais e de poder dentro das organizações. Dwyer (2006) identificou as relações sociais estabelecidas no local de trabalho na forma de recompensa, de comando e da organização como determinantes nas origens dos acidentes. Por exemplo, o sistema de recompensas (financeiro ou simbólico), que predomina em determinado grupo, pode determinar a ocorrência de acidentes, na medida em que estas recompensas reforcem práticas, procedimentos ou comportamentos perigosos ou de risco. Outro fator refere-se ao comando e relações de poder. Esta influência é exercida por estilos de gestão mais autoritários e controladores, que de uma forma direta ou indireta apenas mostram uma preocupação com a produção e transformam o perigo e o risco numa parte normal do trabalho. Em outro exemplo, sobre o nível de organização do trabalho, salienta o ambiente de trabalho gerado pelo empregador, que quando caracterizado pelo recurso de mão de obra pouco qualificada, ou atividades rotineiras e repetitivas, ou a existência de desorganização, constituem fatores que podem dar origem aos acidentes.

Como descrito acima, nos últimos anos houve uma evolução da análise dos acidentes, ampliando as fronteiras da análise com ênfase comportamentalista (atos inseguros) dos trabalhadores, que leva à culpabilização do indivíduo e à ideia da inevitabilidade dos acidentes, para um olhar organizacional ou sistêmico, sendo esta a tendência das análises de acidentes no mundo. O Quadro 1 resume as principais de abordagens de análise de acidentes apresentados acima, que servirão como base para análise dos relatórios objeto desta pesquisa.

\section{Método}

Os Auditores Fiscais do Trabalho (AFT) do Ministério do Trabalho e Emprego (MTE) têm como competência legal, entre outras, a análise de acidentes que tenham relação direta ou indireta com o trabalho, conforme o Regulamento de Inspeção do Trabalho, Art. 18, inciso XIV (Brasil, 2002). Esta competência lhes confere a prerrogativa de acessar todos os documentos relativos a esses eventos que possam contribuir para sua compreensão. Entre esses documentos estão os relatórios de análises de acidentes realizadas por integrantes do sistema de produção onde ocorreu o evento.

Os autores desta pesquisa, como exercem a atividade de AFT, tiveram acesso durante o exercício da função a esses relatórios de análise de acidentes, que foram utilizados como referência para conhecer o tipo abordagem adotada nas análises de acidentes realizadas pelos sistemas de produção instalados no Estado da Bahia. Os sistemas de produção eram selecionados conforme houvesse informação de ocorrência de acidentes por denúncia ou pelos bancos de dados disponíveis no MTE.

Para a análise qualitativa dos relatórios, foi elaborado um formulário de dados, para o qual os autores transcreveram de cada relatório as causas dos acidentes e as medidas de ação propostas, dados considerados essenciais para categorizar o tipo de abordagem adotado nas análises dos acidentes.

As causas dos acidentes e as medidas de ações transcritas dos relatórios analisados para o formulário foram classificadas quanto à origem em: centrada no indivíduo, técnica e organizacional ou sistêmica. Após esta classificação, foi realizado um cotejamento das causas e ações classificadas com relação à origem com os tipos de abordagens constante no Quadro 1. As análises dos acidentes foram categorizadas em 
centrada no indivíduo e organizacional ou sistêmica, conforme a classificação das causas dos acidentes e as medidas de ações apontassem para um tipo de abordagem descrita naquele quadro.

A classificação das causas dos acidentes e as medidas de ações quanto à origem foram realizadas da seguinte forma:

Centrada no indivíduo - causas com expressões que enfatizam o comportamento do indivíduo, tais como "falta de atenção", "excesso de confiança", "descuido", "não usar o EPI". E ações que visam influenciar no comportamento do indivíduo, como "treinamento", "conscientizar", "orientar".

Técnica - causas com origem na falha ou quebra de equipamento ou material, ou falhas de procedimento. Ações que visam consertar ou melhorar o funcionamento de um equipamento ou material, ou melhorar procedimentos técnicos ou de segurança.

Organizacional ou sistêmica - causas com origens na falha ou deficiência na gestão de segurança ou de manutenção ou da produção do sistema de produção. Ações que visam corrigir as falhas ou melhorar a eficiência da gestão de segurança ou de manutenção ou de produção do sistema de produção.
Em resumo, foi seguida a seguinte estratégia de coleta e análise dos relatórios:

a) Solicitado ao sistema de produção os relatórios de análise de acidentes de determinado período.

b) As causas dos acidentes e as medidas de ações contidas nos relatórios foram transcritas para um formulário de dados.

c) As causas dos acidentes e as medidas de ações transcritas dos relatórios analisados para o formulário foram classificadas quanto à origem em: centrada no indivíduo, técnica $\mathrm{e}$ organizacional ou sistêmica.

d) Foi realizado um cotejamento das causas e ações classificadas com relação à origem com os tipos de abordagens constante no Quadro 1.

e) As análises dos acidentes foram categorizadas em centrada no indivíduo ou organizacional ou sistêmica, conforme a classificação das causas dos acidentes e as medidas de ações apontassem para um tipo de abordagem descrita naquele quadro.

Quadro 1. Resumo das abordagens de análise de acidentes.

\begin{tabular}{|c|c|c|c|}
\hline Tipo de Abordagem & Aspecto da concepção de acidentes & $\begin{array}{c}\text { Medidas de prevenção } \\
\text { adotadas }\end{array}$ & Autores \\
\hline Centrada no individuo & $\begin{array}{l}\text { Ênfase em atos inseguros e lesões pessoais. } \\
\text { Origens de erros em fatores psicológicos } \\
\text { (desatenção, esquecimento, falha na } \\
\text { motivação, descuido, desconhecimento, } \\
\text { inexperiência, negligência, não } \\
\text { cumprimento dos procedimentos, etc.). } \\
\text { Causa única, ou poucas causas, ou tem } \\
\text { origem centrada no indivíduo ou tem uma } \\
\text { origem técnica. Resulta do descumprimento } \\
\text { de normas de segurança ou prescrições com } \\
\text { origens em aspectos individuais. Modelo } \\
\text { centrado na pessoa, comportamentalista ou } \\
\text { psicologizante. }\end{array}$ & $\begin{array}{l}\text { Campanhas de apelo } \\
\text { no medo. Recompensa, } \\
\text { punição, auditorias de } \\
\text { atos inseguros, seleção e } \\
\text { treinamento. }\end{array}$ & $\begin{array}{l}\text { Greenwoode } \\
\text { Woods, } \\
\text { Heinrich } \\
\text { (Cooper, 1998) }\end{array}$ \\
\hline $\begin{array}{l}\text { Organizacional ou } \\
\text { sistêmica }\end{array}$ & $\begin{array}{l}\text { Os erros são mais consequência do que } \\
\text { causa. Os acidentes são sintomas de } \\
\text { condições latentes presentes no sistema } \\
\text { antes da sua ocorrência (decisões relativas } \\
\text { à escolha de tecnologias e materiais usados } \\
\text { no sistema, políticas adotadas, práticas } \\
\text { de manutenção, gerenciamento de risco). } \\
\text { Devem ser considerados e analisados, } \\
\text { durante a investigação dos acidentes, } \\
\text { aspectos da história da organização. }\end{array}$ & $\begin{array}{l}\text { Medidas proativas e } \\
\text { melhoria contínuas no } \\
\text { sistema de segurança e } \\
\text { dos processos básicos do } \\
\text { sistema produção. }\end{array}$ & $\begin{array}{l}\text { Turner \& } \\
\text { Pidgeon } \\
\text { (1997), Perrow } \\
\text { (1999), Reason } \\
\text { (1997), Llory } \\
(1999)\end{array}$ \\
\hline $\begin{array}{l}\text { Acidentes como } \\
\text { socialmente } \\
\text { produzidos }\end{array}$ & $\begin{array}{l}\text { As relações sociais estabelecidas no local } \\
\text { de trabalho na forma de recompensa, } \\
\text { de comando e da organização como } \\
\text { determinantes nas origens dos acidentes. }\end{array}$ & $\begin{array}{l}\text { Melhoria das relações } \\
\text { sociais existentes no sistema } \\
\text { de produção. }\end{array}$ & Dwyer (2006) \\
\hline
\end{tabular}

Fonte: Elaborado pelos autores (2013). 


\section{Resultados}

Foram analisados 85 relatórios de análise de acidentes de 46 sistemas produção. Os relatórios foram elaborados entre 2009 e 2013, período em que um dos autores coordenou o projeto de análise de acidentes do MTE no Estado da Bahia. Como eram solicitados os relatórios de análise de acidente ocorridos em determinado período, de acordo com os objetivos da auditoria fiscal, os sistemas de produção apresentavam o número de relatórios correspondentes à quantidade de acidentes ocorridos no período solicitado, por isso consta na Tabela 1 sistemas de produção com mais de um relatório.

Os sistemas de produção constantes na Tabela 1 são reconhecidos pelos altos riscos inerentes a suas atividades, como o transporte aéreo de passageiro, saneamento, indústria de petróleo, indústria da construção, serviço florestal, concessionário de energia elétrica, manutenção de instalação elétrica de alta-tensão, extração de minérios, geração e transmissão de energia elétrica e estocagem de produtos químicos.

A Tabela 2 mostra que dos 85 dos relatórios analisados, $18(21,2 \%)$ eram relativos a acidentes em que houve vítimas fatais, 62 (72,9\%) eram de acidentes em que houve necessidade de afastamento da vítima do trabalho devido às consequências do evento e $05(5,9 \%)$ eram acidentes em que não houve necessidade de afastamento do acidentado de suas atividades.

Não foi identificado um padrão de relatório entre os sistemas de produção. Dos relatórios analisados, $81(95,3 \%)$ identificaram as causas do acidente, $75(88,2 \%)$ apresentaram ações para evitar novas ocorrências e $10(11,8 \%)$ não apresentaram medidas de ações preventivas. A Tabela 3 mostra a quantidade de causas presentes nos relatórios analisados.

Dos 85 relatórios analisados, $4,7 \%$ relatórios não apresentavam causas para o acidente, $28,2 \%$ relatórios apresentavam apenas 01 causa, 28,2\% relatórios apresentavam $02,18,8 \%$ apresentavam 03 , $11,8 \%$ apresentavam $4,5,9 \%$ apresentavam 05 , $1,2 \%$ apresentava 06 e 1,2\% apresentava 09 causas. No total, foram identificadas 201 causas, que dá uma média de 2,4 causas por relatório analisado.

A Tabela 4 mostra que a maioria das causas informadas nos relatórios é centrada no indivíduo $(45,8 \%)$, seguida pelas causas de origem técnica $(34,8 \%)$ e em menor número as causas de origem organizacional ou sistêmica $(19,4 \%)$.

Tabela 1. Quantidade de sistemas de produção $\left(\mathrm{n}_{1}=35\right)$ e de relatórios de acidentes avaliados no Estado da Bahia $\left(\mathrm{n}_{2}=71\right)$.

\begin{tabular}{|c|c|c|}
\hline Tipo de Sistema Produção & $\begin{array}{c}\text { Quantidade Sistema } \\
\text { Produção }\end{array}$ & $\begin{array}{c}\text { Quantidade de } \\
\text { Relatórios }\end{array}$ \\
\hline Transporte aéreo de passageiro & 01 & 15 \\
\hline Fabricação de cadeados e fechaduras para porta & 01 & 03 \\
\hline Água, esgoto e saneamento & 01 & 08 \\
\hline Indústria de Petróleo & 01 & 01 \\
\hline Indústria da Construção & 12 & 15 \\
\hline Indústria de Alimentos & 01 & 01 \\
\hline Aluguel de máquinas de elevação de material & 01 & 01 \\
\hline Serviço florestal & 01 & 01 \\
\hline Concessionária de energia elétrica & 01 & 03 \\
\hline Manutenção de instalações elétricas de alta-tensão & 08 & 09 \\
\hline Extração e beneficiamento de minério & 02 & 03 \\
\hline Manutenção predial & 02 & 02 \\
\hline Construção de rede de energia elétrica & 01 & 01 \\
\hline Fabricação de pneumáticos & 01 & 01 \\
\hline Geração e transmissão de energia elétrica & 01 & 04 \\
\hline Estocagem de produtos químicos & 01 & 01 \\
\hline Fabricação de acessórios para indústria automotiva & 02 & 05 \\
\hline Prestação de serviços para indústria de petróleo & 01 & 02 \\
\hline Fabricação de peça metálica & 01 & 01 \\
\hline Produção de fertilizantes & 01 & 02 \\
\hline Beneficiamento de grão & 04 & 05 \\
\hline Indústria agrícola & 01 & 01 \\
\hline Total & 46 & 85 \\
\hline
\end{tabular}

Fonte: Elaborado pelos autores (2013). 
Tabela 2. Tipos de acidentes reportados.

\begin{tabular}{lcc}
\hline \multicolumn{1}{c}{ Tipo de Acidente } & Quantidade & Percentual \\
\hline Fatal & 18 & $21,2 \%$ \\
Com afastamento do & 62 & $72,9 \%$ \\
acidentado & & \\
$\begin{array}{l}\text { Sem afastamento do } \\
\text { acidentado }\end{array}$ & 05 & $5,9 \%$ \\
Total & 85 & $100 \%$ \\
\hline
\end{tabular}

Fonte: Elaborado pelos autores (2013).

Tabela 3. Quantidade de aspectos causais presentes nos relatórios analisados.

\begin{tabular}{lcc}
\hline \multicolumn{1}{c}{$\begin{array}{c}\text { Quantidade de } \\
\text { causas }\end{array}$} & $\begin{array}{c}\text { Quantidade } \\
\text { de relatórios }\end{array}$ & Percentual \\
\hline Até duas causas & 52 & $54,8 \%$ \\
$\begin{array}{l}\text { De três a cinco } \\
\text { causas }\end{array}$ & 31 & $42,4 \%$ \\
$\begin{array}{l}\text { Mais de cinco } \\
\text { causas }\end{array}$ & 02 & $2,8 \%$ \\
Total & 85 & $100 \%$ \\
\hline
\end{tabular}

Fonte: Elaborado pelos autores (2013).

Tabela 4. Origens das causas dos acidentes identificadas nos relatórios $(n=201)$.

\begin{tabular}{lcc}
\hline Origem das causas & $\begin{array}{c}\text { Causas } \\
\text { identificadas }\end{array}$ & Percentual \\
\hline Centrada no & 92 & $45,8 \%$ \\
indivíduo & & \\
Técnica & 70 & $34,8 \%$ \\
Organizacional ou & 39 & $19,4 \%$ \\
sistêmica & & \\
Total & 201 & $100 \%$ \\
\hline
\end{tabular}

Fonte: Elaborado pelos autores (2013).

Entre as causas centradas no indivíduo, as mais frequentes são "falta de atenção" $(21,7 \%)$, "não cumprir o procedimento" (16,3\%), "excesso de confiança" (7,6\%), "não usar o EPI" e "não usar o EPI de forma correta" com frequências 7,6\% e $4,4 \%$, respectivamente. Os dados são apresentados na Tabela 5. Os termos constantes nesta tabela foram transcritos como se encontram no relatório, por isso estão entre aspas.

Foram relatadas 166 ações com o objetivo de prevenção de novos acidentes. Dessas ações, $50,0 \%$ estão dirigidas para agir sobre o indivíduo, 28,9\% são de ordem técnica e $21,1 \%$ são de ordem organizacional ou sistêmica. Os dados são apresentados na Tabela 6.

As ações mais frequentes entre aquelas centradas no indivíduo são: "diálogo diário de segurança" (28,9\%), "treinamento" (25,3\%), "reciclar" $(10,8 \%)$, "orientar" $(9,6 \%)$ e "conscientizar" $(6,0 \%)$. Os dados constam na Tabela 7. Também nesta tabela os termos estão entre aspas, porque foram transcritos como estavam nos relatórios.
Tabela 5. Causas de origem centrada no indivíduo mais frequentes $(n=92)$.

\begin{tabular}{|c|c|c|}
\hline Causa & Frequência & Percentual \\
\hline "Falta de atenção" & 20 & $21,7 \%$ \\
\hline $\begin{array}{l}\text { "Não cumprir o } \\
\text { procedimento" }\end{array}$ & 15 & $16,3 \%$ \\
\hline $\begin{array}{l}\text { "Excesso de } \\
\text { confiança" }\end{array}$ & 07 & $7,6 \%$ \\
\hline "Não usar o EPI" & 07 & $7,6 \%$ \\
\hline $\begin{array}{l}\text { "Não usar o EPI de } \\
\text { forma correta" }\end{array}$ & 04 & $4,4 \%$ \\
\hline Outros & 39 & $42,4 \%$ \\
\hline Total & 92 & $100 \%$ \\
\hline \multicolumn{3}{|c|}{ Fonte: Elaborado pelos autores (2013). } \\
\hline \multicolumn{3}{|c|}{ Tabela 6. Ações informadas nos relatórios ( $n=166)$. } \\
\hline Ações & $\begin{array}{c}\text { Ações } \\
\text { identificadas }\end{array}$ & Percentual \\
\hline $\begin{array}{l}\text { Centradas no } \\
\text { indivíduo }\end{array}$ & 83 & $50,0 \%$ \\
\hline Técnicas & 48 & $28,9 \%$ \\
\hline $\begin{array}{l}\text { Organizacionais ou } \\
\text { sistêmicas }\end{array}$ & 35 & $21,1 \%$ \\
\hline Total & 166 & $100 \%$ \\
\hline
\end{tabular}

Fonte: Elaborado pelos autores (2013).

Tabela 7. Ações centradas no indivíduo mais frequentes $(n=70)$.

\begin{tabular}{lcc}
\hline \multicolumn{1}{c}{ Ações } & Frequência & Percentual \\
\hline $\begin{array}{l}\text { "Diálogo diário de } \\
\text { segurança" }\end{array}$ & 24 & $28,9 \%$ \\
"Treinamento" & 21 & $25,3 \%$ \\
"Reciclar" & 09 & $10,8 \%$ \\
"Orientar" & 08 & $9,6 \%$ \\
"Conscientizar" & 05 & $6,0 \%$ \\
Outros & 16 & $19,4 \%$ \\
Total & 83 & $100 \%$ \\
\hline
\end{tabular}

Fonte: Elaborado pelos autores (2013).

\section{Discussão}

O fato de não existir um padrão de relatório de análise de acidente dificulta a sua análise, pois uns apresentam ações de prevenção, com os responsáveis para implementá-las, outros não apresentam ações. Alguns apresentam o método utilizado para análise do acidente, mas há relatórios onde não é possível identificar como as causas foram levantadas, ou não foram identificadas as causas do acidente.

As análises de acidentes apresentadas nos relatórios são na maioria unicausal ou pauci-causal (poucas causas), pois mais da metade $(54,8 \%)$ apresentaram no máximo duas causas, e a média foi de 2,4 causas 
informadas por relatório. Estudos anteriores realizados por Binder et al. (1997) no Estado de São Paulo e Almeida (2001) na cidade de Botucatu/SP, encontraram 1,14 e 1,68 causas por evento, respectivamente. $\mathrm{O}$ discreto aumento no número de causas em relação aos estudos anteriores pode ser explicado por casos localizados de sistema de produção que realizaram análises que resultaram em número elevado de causas. Estes achados indicam que houve pequenos avanços nas análises de acidentes nos últimos 15 anos.

A predominância da abordagem de análise centrada no indíviduo fica mais evidente quando se observa que as causas de origem humana $(45,8 \%)$ e de origem técnica $(34,8 \%)$, características desta abordagem, são a grande maioria. Juntas essas causas atingem $80,6 \%$ das causas informadas, ante $19,4 \%$ das causas com origem na organização, que caracteriza a abordagem organizacional ou sistêmica. Pesquisa de Binder et al. (1997) referente às análises de acidentes em sistema produtivos no Estado de São Paulo permite comparação com esses achados. Em $72 \%$ dos casos, a "causa" atribuída para o acidente, naquele estudo, foi relacionada a comportamentos do acidentado. O estudo de Almeida (2001) achou que $51 \%$ das causas são de origem humana. Estudo realizado por Vilela et al. (2004), que analisaram relatórios de análise de acidentes do Instituto de Criminalística da Cidade de Piracicaba do Estado de São Paulo, mostrou que 56,3\% das causas tiveram origem no indivíduo. Os dados apontados mostram diminuição da proporção de causas atribuídas a comportamentos do acidentado, mas elas continuam representando quase a metade das causas apuradas.

Outro dado que reforça a predominância da abordagem centrada no indivíduo é maior frequência de fatores relacionados ao comportamento entre as causas de origem humana, como a "Falta de atenção" $(21,7 \%)$, "Não cumprir o procedimento" $(16,3 \%)$ e "Excesso de confiança" (7,6\%), fatores típicos daquela abordagem. Fatores semelhantes, como "Descuido", "Falta de atenção", "Falta cuidado", "Erro", "Imprudência" foram também encontrados na pesquisa de Almeida (2001), o que demonstra a persistência da abordagem centrada no indivíduo no Brasil, apesar tendência mundial de ampliar a fronteira da análise de acidente.

As ações com foco no individuo, em consonância com as causas de origem humana, são a maioria entre as ações informadas nos relatórios analisados. Elas são $50 \%$ das ações relatadas ante $21,1 \%$ das ações voltadas para intervir na organização. Neste estudo, a proporção de medidas dirigidas a mudanças de comportamento dos acidentados foi inferior à observada no estudo de Binder et al. (1997) e por Almeida (2001), que atingiram $72,9 \%$ e $55,3 \%$, respectivamente. Observa-se, portanto, que há uma queda das ações dirigidas à mudança do comportamento, mas elas ainda continuam sendo a maioria.

Entre as ações com foco no indivíduo, aquelas de maior frequência são as que têm o objetivo de intervir no comportamento da pessoa, como "Diálogo diário de segurança" (28,9\%), "Treinamento" $(25,3 \%)$, "Reciclar" (10,8\%) e "Orientar" (9,6\%). Esses dados reforçam a predominância da abordagem centrada no indivíduo nas análises de acidentes pesquisadas. Essas ações são condições necessárias, mas não suficiente, para a implementação de mudanças de comportamento com vista à prevenção de acidentes. As ações propostas nos sistemas de produção estudados foram genéricas e semelhantes às encontradas nos estudos de Binder et al. (1997) e Almeida (2001).

Segunda Almeida (2006), a persistência da abordagem centrada no indivíduo "também chama a atenção pelo fato de concentrar-se em recomendações de prevenção classificadas como de baixa estabilidade no tempo ou uso isolado de medidas ativas". Ainda segundo Almeida (2006), nas situações em que o sistema de trabalho mantém-se inalterado, o acompanhamento da implantação dessas medidas pode revelar a recorrência de acidentes com aspectos assemelhados, ou seja, o esgotamento do alcance dessas recomendações.

Os dados que constam neste estudo mostram que a abordagem centrada no indivíduo, monocausal ou com poucas causas, vem persistindo nos sistemas de produção, apesar de diversos estudos evidenciarem suas limitações para a prevenção. Quais as razões para esta persistência? Não seria uma demonstração de que esta abordagem é conveniente e interessante para esconder as verdadeiras causas dos acidentes de trabalho?

Por que a abordagem de análise de acidente centrada no indivíduo persiste no meio técnico dos sistemas de produção? Responder esta pergunta é importante para o diagnóstico da situação atual e, principalmente, para a superação de entraves que limitam o avanço de abordagens mais abrangentes e adequadas à prevenção dos acidentes de trabalho.

Uma resposta para esta questão seria a falta de interesse dos sistemas de produção em admitir as falhas organizacionais ou sistêmicas. O comportamento da vítima é relacionado com o acidente de trabalho, para não expor o sistema de produção a demandas judiciais e para não serem tomadas medidas que evitem novos acidentes, pois é mais vantajoso para a empresa culpar o trabalhador do que gastar com ações que implicam gasto financeiro direto ou indireto. Se as causas do acidente estão relacionadas com as vítimas, nada precisa ser feito para mudar o sistema de gestão de segurança, mantendo as mesmas condições de trabalho. Gérard Mendel (1999, p. 3), em seu prefácio do livro Acidentes industriais. $O$ custo do silêncio, considera surpreendente a persistência da concepção restrita ao fator humano e afirma: "Pode-se achar que, nessa 
cegueira maciça, existe mais do que a preocupação, sem dúvida presente, de poupar a hierarquia [...]."

Segundo Garza \& Fadier (2007), se a noção de "erro humano" continua presente nas empresas, é em parte porque há duas modalidades de ação adotadas em paralelo após o acidente. Trata-se da investigação jurídica, que tem por objetivo determinar as responsabilidades, e da investigação de prevenção, que tem por objetivo analisar e compreender o evento, com o fim de reduzir ou eliminar as causas identificadas. A dominância da investigação jurídica nesse contexto faz com que o erro humano seja posto em destaque.

Outras respostas para essa questão são propostas por Reason et al. (2001). Segundo esses autores, a persistência na atribuição da culpa origina-se de quatro grupos de fatores psicológicos: 1) atribuição fundamental de erro, isto é, a tendência de atribuir erros de desempenho a aspectos de personalidade e/ou das capacidades da pessoa que os comete, considerada descuidada, irresponsável, incompetente; 2) ilusão da vontade livre, entendida como a crença de que as pessoas são, em larga escala, as controladoras de seus próprios destinos e capazes de escolher entre os cursos corretos e incorretos de suas ações; 3 ) hipótese do mundo justo, ou seja, a crença de que as coisas ruins acontecem às pessoas que as merecem e 4) distorção da análise retrospectiva, isto é, a tendência de acreditar que eventos passados eram mais previsíveis do que realmente o eram.

Segundo Pidgeon \& O'Leary (2000), outra questão que deve ser levantada é a resistência muito grande das empresas em aprender com os acidentes e os erros do passado. Duas barreiras para este aprendizado são: 1) dificuldade de informação e 2) imputação da culpa e políticas organizacionais.

Outro fator que pode contribuir para esse tipo de análise é a insuficiência técnica na formação dos profissionais que atuam nas empresas em questão. Essa hipótese revela-se particularmente preocupante, por tratar-se de insuficiência na capacidade de Técnicos de Segurança e/ou Engenheiros de Segurança para a identificação de riscos e/ou perigos que podem ser definidos como óbvios ou evidentes. É de responsabilidade das empresas capacitar esses profissionais para a realização de análises de acidentes.

E quais seriam as características de uma boa análise de acidentes? Existem na literatura muitas propostas para uma boa análise de acidentes, a mais conhecida e recomendada é a proposta pela Health and Safety Executive (Brasil, 2003), instituição que trata do tema no Reino Unido e estabelece os seguintes dados essenciais em uma boa análise: 1) adotar uma abordagem organizacional ou sistêmica; 2) envolver os diversos níveis hierárquicos; 3 ) utilizar protocolos para estruturar e dar suporte à análise; 4) identificar causas imediatas e subjacentes; 5) desenvolver recomendações para causas imediatas e básicas; 6) implementar recomendações e atualizar avaliações de riscos relevantes; 7) acompanhar resultados das ações implementadas para redução de risco de acidentes futuros; 8) providenciar retroalimentação (feed-back) e compartilhar o aprendizado imediato; 9) desenvolver bancos de dados acessíveis.

O documento denominado "Report Profile" (Brasil, 2003) que trata de análises de eventos que envolvam substâncias perigosas (Convenção OIT $n^{\circ} 174$ e Recomendação OIT $n^{\circ} 181$ ), principalmente em países europeus, com o objetivo de constituir banco de dados internacional minimamente uniformizado, propõe um relatório constituído das seguintes partes:

- Identificação da empresa onde ocorreu o acidente.

- Resumo ou perfil do acidente (em uma página): inclui campos para descrição do tipo de acidente, substância diretamente envolvida, origens imediatas do acidente, causas suspeitas (da fábrica ou equipamentos, humanas, ambientais ou outras, natureza de defeitos, erros, falhas, sequência de eventos, etc.), efeitos imediatos, medidas emergenciais adotadas e lições imediatas aprendidas a partir da ocorrência.

- Análise do acidente organizada em três partes: ocorrência, consequências e resposta.

A ocorrência é subdividida em tipo de acidente, inventário de substâncias perigosas direta e indiretamente envolvidas, origens do acidente, condições meteorológicas, causas principais (técnicas, humanas e organizacionais) e discussão. Essa proposta não se aplica a instalações nucleares ou militares, nem ao transporte de substâncias perigosas fora das instalações (exceto quando por tubulações)

As orientações de preenchimento enfatizam cuidadosa descrição das condições físicas e operacionais do sistema, assim como a necessidade de identificar as substâncias envolvidas, suas quantidades e esclarecer os aspectos técnicos do acidente (materiais iniciadores, intermediários, produtos finais, possíveis produtos anormais, etc.).

A descrição da origem do acidente deve incluir ilustrações como mapas, fotos e outras informações relativas à instalação e sua vizinhança. Além disso, deve indicar, com uso de classificação internacional, o tipo de indústria, atividade e de seus componentes. No campo destinado a observações devem-se expandir as informações, indicando a última modificação ou manutenção realizada e o tempo decorrido desde então, o design dos padrões, as condições de processo ou armazenamento, se em operação, manutenção ou outra influência especial. 
As conclusões acerca das causas principais são firmadas em termos de categorias:

- Operacionais - falhas de componentes materiais ou equipamentos, reações aceleradas ou inesperadas, perdas de controle, etc.

- Ambientais - mudanças climáticas, falhas ou deficiências de proteções, interferência de outro acidente, etc.

- Organizacionais - inadequações no gerenciamento da organização ou de atitudes, falhas em procedimentos, treinamentos, supervisão, suporte, análise de processos, construção de instalações, sistema de isolamento de equipamentos, manutenção, etc.

- Pessoais - erros, problemas de saúde, desobediências, intervenção maliciosa e outras. Recomenda-se que, sendo necessário, sejam detalhados aspectos relativos a treinamento, experiência, etc.

Um bom método deve prover maneiras adequadas de sistematizar a análise, particularmente a coleta de dados, de sorte que os principais aspectos que possam ter contribuído para o desencadeamento do acidente sejam identificados e adequadamente descritos e caracterizados. Pode-se comparar a análise de um acidente à abertura de uma caixa-preta com o objetivo de observar, catalogar e caracterizar seu conteúdo.

\section{Evoluindo para a gestão proativa da segurança}

O que se faz geralmente nas empresas, comprovado por meio do conhecimento empírico dos autores e revelado pelos relatórios de análises de acidentes, são "auditorias de segurança" que permitem medir o nível de segurança global da empresa e, eventualmente, orientar a sua política global. Essas auditorias são pouco eficazes, pois se limitam com frequência a um levantamento dos afastamentos ao prescrito (procedimentos, regras de segurança, uso dos equipamentos de proteção individual), mas raramente fazem uma análise da relação homem-máquina, das condições de trabalho, dos objetivos, das metas e aos resultados impostos pela empresa. Assim, a gestão de segurança encontrada é reativa e guiada por dados do passado (Svedung \& Rasmussen, 2002). No entanto, a gestão de segurança deve evoluir para a análise perspectiva do trabalho, conhecendo-o para transformá-lo antes da ocorrência do acidente. A empresa deve se orientar para uma prevenção global do sistema, interrogando-se, portanto, sobre o gerenciamento da segurança e sobre a confiabilidade organizacional. Nesse contexto, a noção de "retorno da experiência" emerge como ferramenta de controle e avaliação do nível de segurança existente. $\mathrm{O}$ retorno da experiência é definido como o conjunto das informações e conhecimento que se pode acumular e constituir de um sistema particular ao longo do tempo e utilizá-lo para a prevenção (aprendendo com a experiência) (Garza \& Fadier, 2007). As análises de acidentes, bem conduzidas, devem constituir uma excelente fonte de informação e aprendizado.

A evolução para a gestão de segurança proativa implica o seguinte:

1. O desenvolvimento proativo de gestão de segurança deve evoluir para abranger um ambiente técnico e social mais amplo, considerando assim a dimensão coletiva do trabalho, as interações sociais existentes no trabalho, as interações entre diferentes equipamentos de trabalho (interfaces, máquinas, etc.), inserindo, desta forma, novas questões na análise. Essas questões dizem respeito tanto à análise das situações de trabalho (trabalho em equipe, comunicações, processos de cooperação, relação de subordinação, etc.) quanto à sua concepção (concepção distribuída, distribuição das tarefas homem-máquina, etc.).

2. Além disso, embora a observação da atividade de trabalho seja suficiente para explicar o mau funcionamento que caracteriza um processo de trabalho e ajude consideravelmente a explicar um acidente ou incidente, outros métodos são necessários para uma abordagem proativa da segurança. Por exemplo, analisar também os constrangimentos da organização (demandas, atrasos de produção, leis, greves, etc.), que podem exercer diferentes pressões sobre o sistema, contribuindo para a ocorrência de acidentes.

3. Assim, ficam evidenciados os fatores organizacionais, erros de concepção ou ainda fatores latentes favorecendo a ultrapassagem das barreiras de segurança. Os "produtores de erros" podem ser numerosos, situar-se em centros de decisões e em níveis hierárquicos diferentes, e estar muito a montante do "posto de trabalho" envolvido e do momento da produção do acidente. Não se trata mais somente da gestão individual do risco em situação de trabalho, mas de uma gestão coletiva da segurança que se inscreve no quadro de uma rede organizacional.

A gestão de segurança reativa está estreitamente vinculada à análise de acidentes e incidentes, mas muito pouco à análise anterior dos riscos. Embora a análise desses eventos seja indispensável e deva 
cumprir seu papel de prevenção, ela se limita ao acidente ou incidente "realizado", ou seja, depois que acontece. Esta natureza de gestão de segurança é característica de organizações que têm cultura de segurança reativa (Gonçalves et al., 2010). Por sua vez, as organizações com cultura de segurança proativa atuam numa perspectiva proativa de segurança e do gerenciamento de risco, procuram antecipar o acidente, para evitar sua ocorrência.

Pesquisas científicas mostram que fatores como compromisso da alta gerência do sistema produtivo com a segurança, o baixo fatalismo, ou seja, acreditar que os acidentes não são fatalidades, a prioridade com a segurança e conscientização da existência de riscos, são atitudes particularmente importantes dos gestores com a prevenção (Gonçalves et al., 2010; Rundmo \& Hale, 2003). No entanto, o que ainda se constata empiricamente na maioria das empresas onde os acidentes acontecem, são gestores que priorizam menos a segurança e mais a produção, que dedicam pouco tempo na gestão da segurança, além de perpetuar na organização a cultura de que os acidentes são obra do acaso e ignorar a existência dos riscos. O reflexo disso é uma gestão reativa da segurança e, consequentemente, em relatórios de análise de acidentes que objetivam mais a dimensão jurídica, imputando a culta no operador e menos a prevenção.

Em resumo, uma iniciativa de prevenção real, proativa e global de um sistema de produção, existente e futuro, necessita cruzar conhecimento e métodos múltiplos, necessita de atitudes da alta gerência que indiquem que a segurança é uma prioridade e está no cerne da cultura da organização.

\section{Conclusão}

Os dados da pesquisa revelam que a abordagem predominante nas análises de acidentes apresentados nos relatórios analisados é a centrada no indivíduo, que tem como característica a identificação de causa única ou poucas causas para os acidentes, as quais têm origens humanas ou têm origens técnicas, apesar de há anos se conhecer a fragilidade dessa forma de análise. Dessa forma, as análises de acidentes realizados pelos sistemas de produção estudados não contribuem com seu objeto primordial: a prevenção efetiva e duradoura. Assim, uma ferramenta importante de gestão de segurança é mal utilizada.

Constata-se com base nos dados apresentados, que os sistemas produção pesquisados não evoluíram com relação à análise de acidentes, continuam ainda presos a uma abordagem de análise que privilegia as ações com foco no indivíduo, que são ações reconhecidamente frágeis e que pouco contribuem para a prevenção.

A ocorrência do acidente de trabalho indica inexistência/insuficiência/falência de mecanismos de prevenção, mas não só. Resta retirar todo o ensinamento possível do acidente por meio de análise cuidadosa do ocorrido. A análise de acidentes de trabalho é considerada ferramenta de gestão de segurança e, por isso, a identificação de fatores causais deve ensejar a adoção de medidas de prevenção e o acompanhamento do impacto dessas medidas.

Como os acidentes de trabalho são um grave problema de saúde pública no mundo contemporâneo e no Brasil em particular, a prevenção desses eventos se faz premente. Uma importante ferramenta de prevenção é a análise de acidente, mas para atingir seus objetivos, é necessário que suas fronteiras sejam ampliadas, não se limitando a identificar causas de origem humana e técnica ou propor medidas de prevenção com foco no individuo.

É necessária a mudança na estratégia da gestão de segurança reativa para proativa, para a adoção de medidas de prevenção dos acidentes de trabalho mais eficazes, duradouras e que se antecipem aos riscos. Por outro lado, deve ser combatida por todos os meios, mas estrategicamente no seio do Estado, a culpabilização das vítimas nas análises sobre os eventos. Nesse sentido, tem havido alguns avanços nos últimos anos. Novas perspectivas acerca da análise de acidentes de trabalho têm sido propostas, como evidencia o teor dos documentos Caminhos da Análise de Acidentes do Trabalho, publicado pelo Ministério do Trabalho em Emprego (Brasil, 2003) e Guia de Análise de Acidente de Trabalho da mesma instituição (Brasil, 2010). Tais ações buscam alterar a premissa de que o acidente é determinado pelo comportamento de um indivíduo, no caso, a própria vítima, e transportar a explicação do evento para a multiplicidade de causas que contribuíram para que este ocorresse. Desse modo, haveria uma evolução na possibilidade de prevenção de novos acidentes, ao contrário da abordagem predominante atualmente de culpabilização dos trabalhadores.

\section{Referências}

Almeida, I. M. (2001). Construindo a culpa e evitando a prevenção: caminhos da investigação de acidentes do trabalho em empresas de município de porte médio. Botucatu, São Paulo, 1997 (Tese de doutorado). Universidade de São Paulo, São Paulo.

Almeida, I. M. (2006). Trajetória da análise de acidentes: o paradigma tradicional e os primórdios da ampliação da análise de acidentes. Interface: Comunicacao, Saude, Educacao, 10(19), 185-202. http://dx.doi. org/10.1590/S1414-32832006000100013.

Amalberti, R. (1996). La conduite des systemes à risques. Paris: Le Travail Humain/Presses Universitaires de France.

Binder, M. C. P., \& Almeida, I. M. (1997). Estudo de caso de dois acidentes do trabalho investigados com 
o método de árvore de causas. Cadernos de Saúde Pública, 13(4), 570-579.

Binder, M. C. P., \& Almeida, I. M. (2003). Acidentes de trabalho: acaso ou descaso? In Mendes, R. Patologia do trabalho (2 ed., Cap. 16, pp. 749-808). São Paulo: Atheneu.

Binder, M. C. P., Almeida, I. M., \& Azevedo, N. D. (1997). Análise crítica de investigações de acidentes do trabalho típicos realizadas por 3 empresas metalúrgicas de grande porte do Estado de São Paulo. Revista Brasileira de Saúde Ocupacional, 85/86, 103-118.

Brasil (2002, 30 de dezembro). Decreto $n^{\circ} 4.552$, de 27 de dezembro de 2002. Aprova o Regulamento da Inspeção do Trabalho (p. 4). Brasília, DF: Diário Oficial da República Federativa do Brasil.

Brasil. Ministério da Previdência e Assistência Social (2001). Máquinas e acidentes de trabalho (Coleção Previdência Social, Vol. 13). Brasília, DF. 86 p.

Brasil. Ministério do Trabalho e Emprego (2003). Caminhos da análise de acidentes do trabalho. Brasília, DF. 105 p.

Brasil. Ministério do Trabalho e Emprego (2010). Guia de análise de acidente de trabalho. Brasília, DF. 75 p.

Cooper, D. (1998). Improving safety culture: a practical guide. Londres: Wiley. 318 p.

Dwyer, T. (2006). Vida e morte no trabalho: acidentes do trabalho e a produção social do erro (1 ed.). Campinas: Unicamp. 407 p.

Garza, C., \& Fadier, E. (2007). Segurança e prevenção: referências jurídicas e ergonômicas. In P. Falzon (Ed.), . Ergonomia (Cap. 10, pp. 124-139). São Paulo: Edgard Blucher.

Gonçalves, A. P., Fo., Andrade, J. C. S., \& Marinho, M. M. O. (2010). A safety culture maturity model for petrochemical companies in Brazil. Safety Science, 48(5), 615-624. http://dx.doi.org/10.1016/j. ssci.2010.01.012.

Guerin, F., Lavilles, A., Daniellou, F., Duraffourg, J., \& Kerguelen, A. (2001). Compreender o trabalho para transformá-lo: a prática da ergonomia. São Paulo: Edgard Blucher. 200 p.

Hale, A., \& Hovden, J. (1998). Management and culture: the third age of safety. A review of approaches to organizational aspects to safety, health and environment. In A. M. Feyer \& A. Williamson (Eds.), Occupational injury: risk, prevention and intervention (Cap. 11, pp. 129-165). London: Taylor \& Francis.

Llory, M. (1999). Acidentes industriais: o custo do silêncio. Rio de Janeiro: Multimais. 300 p.
Mendel, G. (1999). Prefácio. In Llory, M. Acidentes industriais: o custo do silêncio (pp. 3). Rio de Janeiro: Multimais.

Moreira, D. A. A. (2009). Administração da produção e operações. São Paulo: Cengage. 624 p.

National Aeronautics and Space Administration - NASA (2003). The accident s organizational causes In National Aeronautics and Space Administration - NASA. Columbia accident investigation board (Report, Vol. 1, Cap. 7, pp. 177-193). Washington: NASA.

Perrow, C. (1999). Normal accidents. Nova Jersesy: Princeton University Press. 439 p.

Pidgeon, N., \& O’Leary, M. (2000). Man-made disasters: why technology and organizations (sometimes) fail. Safety Science, 34(1-3), 15-30. http://dx.doi. org/10.1016/S0925-7535(00)00004-7.

Reason, J. (1997). Managing the risks of organizational accidents. Inglaterra: Ashgate Publishing Limited. $252 \mathrm{p}$.

Reason, J. (2006). Human error (17 ed.). Nova York: Cambridge University Press. 302 p.

Reason, J. T., Carthey, J., \& Leval, M. R. (2001). Diagnosing "vulnerable system syndrome": an essential prerequisite to effective risk management. Quality in Health Care, 10(Supl 2), ii21-ii25. PMid:11700375.

Rundmo, T., \& Hale, A. R. (2003). Managers' attitudes towards safety and accident prevention. Safety Science, 41(7), 557-574. http://dx.doi.org/10.1016/ S0925-7535(01)00091-1.

Sarkus, D. J. (2001). Safety and psychology: where do we go from here? Professional Safety, 46(1), 18-25.

Silva, S. C. A. (2003). Cultura de Segurança e prevenção de acidentes de trabalho numa abordagem psicossocial: valores organizacionais declarados e em uso (Tese de doutorado). Instituto Superior de Ciências do Trabalha e da Empresa, Lisboa.

Svedung, I., \& Rasmussen, J. (2002). Graphic representation of accident scenarios: mapping system structure and the causation of accidents. Safety Science, 40(5), 397-417. http://dx.doi.org/10.1016/S09257535(00)00036-9.

Turner, B. A., \& Pidgeon, N. F. (1997). Man-made disasters (2 ed.). Great Britain: Butterworth-Heinemann. 249 p.

Vilela, R. A. G., Iguti, A. M., \& Almeida, I. M. (2004). Culpa da vítima: um modelo para perpetuar a impunidade nos acidentes do trabalho. Cadernos de Saúde Pública, 20(2), 570-579. http://dx.doi.org/10.1590/ S0102-311X2004000200026. 